\title{
AMPHIBIANS AS MODEL ORGANISMS FOR STUDY ENVIRONMENTAL GENOTOXICITY
}

\author{
BURLIBAŞA, L. ${ }^{*}-$ GAVRILĂ, L. \\ University of Bucharest, Faculty of Biology, Romania \\ (phone: +40 213181565) \\ *Corresponding author \\ e-mail: liliana_burlibasa@yahoo.com.au \\ (Received $17^{\text {th }}$ August 2010; accepted $28^{\text {th }}$ January 2011)
}

\begin{abstract}
Animals, the silent sentinels, stand watch over the world's environmental health. Everyday, animals demonstrate intricate connections between them, us and our surroundings. Amphibians are vertebrates and include approximately 4400 existing species. Amphibians are in most cases, small, diverse and sensitive to environmental variability. They can be good indicators of habitat diversity, biological variety and local stressors on the environment. They are bathed in both water and air. They live outdoors on land and water and their skin, larvae and unshelled eggs are constantly exposed and in contact with the substances in their surroundings. We searched Web of Science and references of relevant publications to evidence the application of amphibians, especially Xenopus laevis as model animal in ecotoxicology.
\end{abstract}

Keywords: amphibians, genotoxicity, ecotoxicology

\section{Introduction}

Environmental toxicology studies of environmental toxicants on the health of all organisms and on the different compartments of the environment. Its concern involves the fact that human survival depends on the preservation of other animal and plant species and on the environmental resources such food, water and fresh air which are menaced mostly by anthropogenic chemicals that alter living organisms and ecological balance.

World Health Organization statistics report that $80 \%$ of human diseases are related to environmental pollution (Pesch et al., 2004; Neubert, 2002; Zhanfen and Xiaobai, 2006). In recent years, there are increasing reports on endocrine disorder, reproductive dysfunction, sexual reversal, environmental deterioration and biodiversity alteration. In this context, ecotoxicology has become in modern times one of the focused issues (Colborn, 2004; Hoyer, 2001). Ecotoxicology is defined by integrating the ecological and toxicological effects of chemical pollutants on biosphere, including humans (Unger, 2003).

Procedures, protocols and testing organisms are important components of environmental technology. The recent establishment of a procedural paradigm for ecological risk assessment (e.g. EPA., 1991) constitutes a technological advance as well as a contribution to ecotoxicology practical goals. General methods to biomonitor (use of organisms to monitor contaminants and to imply possible effects to biota or sources of toxicants to humans (Goldberg, 1986) and apply biomarkers (cellular, tissue, body fluid, physiological or biochemical changes in individuals that are used quantitatively during biomonitoring to imply presence of significant pollutants or as early warning systems for imminent effects) are also important technologies developed in the last several decades. 
One of the major problems in biomonitoring genotoxic pollutants is the choice of test organisms. Unequal sensitivity among species caused by metabolic rates, physiological conditions and target organs can yield misleading results.

Conventional test animals used in ecotoxicology include alga, earthworm, fish, avian species and mouse. Corresponding test methods of these animals are relatively mature and have definite application range. For example, alga test is suitable for assessing toxicities of organic pollutants in water environment, and fish test is suitable for assessing toxicity of more pollutants, while rat/mouse can provide plentiful toxicological data on pollutants. In recent years, more and more scholars have focused on ecotoxic effects of pollutants on amphibians.

\section{Amphibians, sentinel animals for environmental genotoxicity}

Amphibians are important model animal species in biology and they are used in studies on early embryonic development and cell biology. Amphibians have played a key role in the elucidation of the mechanisms of early development over the last century. Much of our knowledge about the mechanisms of vertebrate early development comes from studies using Xenopus laevis. The recent development of a remarkably efficient method for generating transgenic embryos is now allowing the study of late development and organogenesis in Xenopus embryos. Xenopus is a major contributor to our understanding of cell biological and biochemical processes, including: (1) chromosome replication; (2) chromatin, cytoskeleton and nuclear assembly; (3) cell cycle progression and intracellular signaling. Amphibian embryos remained the embryos of choice for experimental embryologists for many decades (Burlibaşa et al, 2005). European embryologists have predominantly used urodele embryos (such as Triturus) and embryos of the frog Rana temporaria, which is related to the North American species Rana pipiens. Amphibian embryos are large, can be obtained in large numbers and can be maintained easily and inexpensively in the laboratory. They are relatively easy to manipulate with microsurgical instruments, and they heal readily after surgery.

In recent years, this model animal species has gradually attracted the attention of more and more ecotoxicologists.

Concerns arising in 1990s about amphibian decline and instances of amphibian malformations have led to an increase in ecotoxicological studies of amphibians. Both aquatic and terrestrial stages are subject to contaminant effects (Unger, 2003).

Amphibians are believed to be sensitive to pollutants because of their highly permeable skin, and their varied lives, which maximize their exposure: they dwell on land and water, and eat both plants and animals at various stages of their life cycle (Conrad, 2010)

The reasons why amphibians and more specifically $X$. laevis is favored by numerous researchers are as follows (Zhanfen and Xiaobai, 2006):

1. Living in water and easily being raised.

2. Ovulating throughout the year and numerous eggs.

3. Large size of eggs - the eggs can be easily observed, collected, transferred and micromanipulated.

4. Fast external development - the process of embryonic development is easily controlled and observed. 
5. Easily manipulation and culturing in vitro - during the embryo period it is relatively easy to isolate specific regions with determined functions and maintain explants in culture media.

6. Transgenic technology availability in Xenopus - many of the experiments using Xenopus in the study of early development have made use of injected mRNA, antibodies, or antisense oligonucleotides. These methods are transient, however, as the genome is not altered and the injected substance decays in time. The biggest leap forward in the establishment of Xenopus as a model organism beyond the limits of early development has been the development of techniques for generating transgenic embryos, by Enrique Amara and Kristen Kroll (1996, 1999, cited by Beck and Slack, 2001). A key advantage of Xenopus transgenesis is the ability to study transgene expression in living embryos using green fluorescent protein (GFP) as a reporter allowing quick and easy promoter analysis.

Fini and his co-workers (2009) developed a real-time flow-through system, based on Fountain Flow cytometry, which measures in situ contaminant-induced fluorescence in transgenic amphibians larvae immersed in water sample. The system requires minimal human effort. This system is portable and selfcontained, allowing on-site measurements.

7. High sensitivity to environmental pollutants - many laboratories have introduced $X$. laevi in ecotoxicological studies.

Due to external fertilization and development, embryos and larvae are more susceptible to environmental pollution because of the direct exposure. Therefore amphibians are regarded as a good sentinel animals for environmental pollution. Martin Ouellet assembled a comprehensive review of the literature on amphibian malformations and from his study we can conclude that most amphibian malformations are frog and toad malformations. Ouellet's search found data on malformations occurring in more frog and toad species, sites, and specimens (Table 1.)

Table 1. Summary of Martin Ouellet's data showing most amphibian malformations are frog and toad malformations (Ouellet et al., 1997; Ouellet, 2000)

\begin{tabular}{|c|c|}
\hline \multicolumn{2}{|c|}{ Frog versus Salamander Ratio } \\
\hline Species affected & $2.6: 1$ \\
\hline Sites where found & $3.7: 1$ \\
\hline Numbers collected & $4.5: 1$ \\
\hline
\end{tabular}

According to the U.S. Geological Survey's National Wildlife Health Center, malformations in amphibians arise from environmental factors that affect individuals at the larval stage of development. Scientists suggest that multiple causes are probably to blame for the malformation instances that have been reported worldwide, and that factors leading to malformations at a particular site may be different from those causing malformations at another site. At this time, the four major environmental factors identified as the causes of malformations are contaminants (chemicals and UV-B radiation, nutritional deficiencies, parasites, and injuries from predators (www.nwhc.usgs.gov). 
As an amphibian species used in laboratory for many years, Xenopus laevis naturally attracts ecotoxicologists' attention. X. laevis embryos have been used to assess early developmental toxicity of environmental pollutants for many years (Frog Embryo Teratogenesis Assay - Xenopus, FETAX)(American Society for Testing and Materials (ASTM), Standard Guide for Conducting the frog Embryo Teratogenesis Assay Xenopus (FETAX), ASTM E1439-98 in Annual Book of ASTM Standards, Philadelphia, 1998)(Zhanfen and Xiaobai, 2006).

\section{Sensitivity to endocrine disruptors}

There is mounting concern in the scientific, environmental and governmental sectors on a wide range of substances, known as endocrine disruptors, that may interfere with the normal functioning of a living organism's endocrine system. Endocrine disruption has the potential to cause reproductive, immunological and neurological problems and in most instances, tumors.

Endocrine disruptors are naturally occurring compounds or man-made chemicals that may interfere with the production or activity of hormones of the endocrine system leading to adverse health effects.

There is some evidence that endocrine disruptors may not only impact the individual directly exposed, but also future generations (Brown and Lamartiniere, 1995).

In 1999, Professor Werner Kloas and his colleagues from Karlsruhe University, Germany, first reported endocrine disruption of phenol substances on Xenopus laevis in 1999 and concluded that this species is suitable for studying endocrine disruption (Lutz and Kloas, 1999; Kloas et al., 1999).

In 2010, Hayes and colleagues published a review of the possible causes of a worldwide decline in amphibian populations, concluding that atrazine (one of the most widely used pesticides all over the world) and other hormone-disrupting pollutants are among likely contributors because they affect the reproductive function and make amphibians more susceptible to disease (Hayes et al., 2010). Many other studies demonstrated that atrazine interferes with endocrine hormones, such as estrogen and testosterone - in fish, amphibians, birds, reptiles, laboratory rodents and even human cell lines at part per billion levels (Hussein et al., 1996; Wilhelms et al., 2005; Solomon et al., 2008).

Atrazine causes adverse effects in amphibians through 1) estrogen-mediated mechanisms, 2) androgen-mediated mechanisms, 3) thyroid-mediated mechanisms, 4) adverse effects on gonadal development in amphibians, or 5) adverse effects at the population level in exposed amphibians (Solomon et al., 2005).

As a result of these studies, the Environmental Protection Agency (EPA) is reviewing its regulations on the use of pesticides. Several states are considering banning atrazine, and six class action lawsuits have been filed seeking to eliminate its use. The European Union has already barred the use of atrazine.

Hayes's studies were the first to show that the hormonal effects of atrazine disrupt sexual development in amphibians. Working with the $X$. laevis, Hayes and his colleagues showed that tadpoles raised in atrazine-contaminated water become hermaphrodites and they develop both female and male gonads (Hayes et al., 2002).

Subsequent studies showed that leopard frogs (Rana pipiens) collected from atrazinecontaminated streams from areas where atrazine was applied, often had eggs in their testes. And many males had lower testosterone levels than normal females and smaller 
than normal voice boxes, presumably limiting their ability to call mates (Hayes et al., 2003).

To understand the process by which endocrine-disrupting chemicals work we must look to the genes. Likein many instances in nature where there are complex interferences between living organisms, a gene is not expressed in isolation but rather in the context of other genes and their products, cells and tissues. This might be thought of as "the ecology of gene expression" (Crews and McLachlan, 2006). It is well known that these chemicals can act on a gene's developmental mechanisms, altering genotype expression. The mechanism of these phenotypic changes is probably epigenetic. In fact, endocrine-disrupting chemicals do not act on genes alone but on developmental mechanisms that integrate genetic and epigenetic interactions, resulting in a particular phenotype.

Hormones are known to epigenetically imprint genes in nonmammalian vertebrates. Working on epigenetic memory with the vitellogenin gene in frogs it was shown that the hormonal treatments applied early in life alter the response of hormonally regulated genes to the same or different hormones later in their life (Edinger et al., 1997). The first hormonal experience epigenetically alters the set point for the later hormone response. This process can be determined, in frogs, by methylation (Andres et al., 1984). The term epigenetic imprinting has also been used to describe a process in which estrogens in development cause persistent alterations in gene expression and reprogram cell fate (Alworth et al., 2002, Huang et al., 2005; Fei et al., 2005; Crews and McLachlan, 2006).

Epigenetic imprinting by endocrine-disrupting chemicals or other hormones represents one potential mechanism for Waddington's concept of genetic assimilation, a direct outgrowth of his research in epigenetics. Waddington speculated that environmentally induced changes in phenotype could become incorporated into the genome as evidenced by the persistence of the phenotype even after the original selection pressure is relaxed (Waddington, 1942, 1953). In this manner the selection might act on developmental pathways leading to adaptive change in the genome in conjunction with genetic mutation. Evidence has emerged in recent years that epigenetically mediated changes in phenotype can be stable over many generations (Crews and McLachlan, 2006). Those epigenetic mechanisms may play a role in endocrine disruption, which helps explain the transgenerational effects of some hormonally active chemicals.

\section{The most used methods for genotoxicity testing on amphibians}

A growing interest in genotoxicity caused by environmental pollutants has led to the development of several biological tests for detecting and identifying genotoxicants in the air, water and soil. Amphibians provide a suitable model for monitoring aquatic genotoxicity and wastewater quality.

\section{Chromosome aberration assay}

Chromosomal mutation is a macrodamage of chromosomes. Chromosome aberration include structural aberrations such as fragments or intercalations and numerical aberrations (unequal segregation of homologous chromosomes during cell divisions, which leads to a loss or surplus of chromosomes (aneuploidy and polyploidy). Cytogenetic effects can be studied either in whole animals ("in vivo") or in cells grown in culture ("in vitro"). Usually, the cell culture is exposed to the test substance and 
afterwards treated with a metaphase-arresting substance (Colcimide). Following suitable staining the cells in metaphase are analyzed microscopically for the presence of chromosomal aberrations.

\section{Micronucleus assay}

Micronuclei are generated from chromosome fragments or whole lagging chromosomes that were not incorporated in the daughter cell nuclei and remained in the cytoplasm after the nuclear envelope of doughter nuclei was reassambled. Micronuclei result either from chromosome breaks or dysfunction of the spindle apparatus or centromere kinetochore complexes, with subsequent elimination of whole chromosomes (aneugenic effects) (Campana et al., 2003). The measurement of micronuclei the cell division must be allowed to continue up to the interphase. Amphibian micronucleus procedure has been standardized (ISO 21427-1:2006). Micronucleus formation along with the sister chromatid exchanges and chromosome aberration assays is considered as a clastogenic endpoint. The principle of flow cytometric measurement of micronuclei was made possible (Kohlpoth et al., 1999, Sánchez et al., 2000) but equipment costs are high. Environmental biomonitoring with micronucleus assays has usually been performed "in vivo" by exposure of relevant aquatic organisms for several days followed by microscopic analysis.

Many results on the Micronucleus assay used in genotoxicity test on amphibians are available (Campana et al., 2003; Mouchet et al., 2009; Fernandez et al., 1993; Arkhipchuk et al. 2000; Krauter et al. 1987; Jaylet et al. 1986; Godet et al. 1996; Djomo et al. 2000).

\section{SCE assay}

The sister chromatid exchange (SCE) assay detects reciprocal exchanges of DNA segments between two sister chromatids of a duplicated chromosome. SCEs represent the interchange of DNA at apparently homologous loci. This process involves DNA breakage and repair but as this process does not necessarily lead to permanent mutations. Some researchers classify the SCE assay as a genotoxicity test. Although little is known about its molecular basis, the SCE frequency is elevated under some pathogenic conditions in humans (e.g Bloom Syndrome) and the influence of mutagenic agents and therefore serves as a model for mutagenicity. The detection of sister chromatids is achieved by incorporation of e.g. bromodesoxyuridine into chromosomal DNA for two cell cycles followed by Hoechst staining and analysis in fluorescence microscopy.

\section{Comet assay}

In recent years the Comet assay has gained broad attention, because the test is relatively easy to handle and can be applied with cells from different organisms and tissues. The alkaline version of the comet assay has been developed by Singh et al. (1989).

The comet assay, also known as the single-cell gel electrophoresis test, is a method of detecting DNA strand breakage (double, single, and alkali-labile sites expressed as single strand breaks) in virtually any nucleated cell. Significant advantages of the comet assay over other genotoxicity tests are its fairly straight forward technique, sensitivity, requirement for small numbers of cells (making the assay conductive to non-lethal testing) and rapid production of data (Tice et al., 2000). Cells are mixed with lowmelting agarose, placed on microscope slides and lysed by an alkaline buffer with ionic 
detergents. The liberated DNA is resolved in an electrophoresis chamber, stained and evaluated by fluorescence microscopy. Cells with increased DNA damage display increased migration from the nuclear region towards the anode. The resulting cometlike structure is quantified by measuring the length of the tail and/or the tail moment (the intensity of the migrated DNA multiplied by the respective tail length (integral) with respect to the nuclear DNA). A review about the applicability of the comet assay in environmental monitoring was provided by Mitchelmore and Chipman (1998). The test has been applied to a broader range of aquatic organisms such as algae (Erbes et al., 1997), mussels (Mitchelmore et al., 1998; Pavlica et al. 2001), amphibians (Ralph and Petras 1998) and fish (Pandrangi et al., 1995; Devaux et al., 1997; Belpaeme et al., 1998; Mitchelmore and Chipman, 1998; Villarini, 1998; Risso-de Faverney et al., 2001; Schnurstein et al., 2001). The advantages of the test are the possibility to choose a broad range of test organisms and tissues, the use of even non-proliferating cells, and the fact that results can be obtained within one day. On the other hand there are still no standard test protocols and a certain degree of handling skills is a necessary prerequisite to routinely performe the test . Although no international accepted standard exists many researchers refer to a test protocol of Tice (1998).

\section{Recent developments}

In the field of genotoxicity evaluation of environmental samples similar developments as in classical toxicology have been undertaken. Fini and coworkers (2009) developed a real-time flow-through system, which measures in situ contaminantinduced fluorescence in transgenic amphibians larvae immersed in water sample. The amplification of DNA by the Polymerase Chain Reaction technique enabled the detection of mutations at specific sites and the development of electrochemical DNAbased biosensors (Kennerley and Parry, 1994; Parsons and Heflich, 1998; Mascini et al., 2001; Picco and Collins, 2008).

Our unpublished yet results revealed that ChIP assay (Chromatin Immunoprecipitation Assay) may offers important informations regarding epigenetic alterations in male newt (Triturus cristatus) spermatogenesis due to environmental exposures.

The micronucleus test and the single cell gel electrophoresis (comet assay) are two most extensively used methods in the detection of genotoxicity of chemicals in the environment. Compared to other assays, they are sensitive, rapid and easy to handle.

Techniques in genetic ecotoxicology are in a rapidly evolving state. Threfore, reliable tools are now available for addressing more complex environmental problems. The increasing availability of reliable diagnostic tools will greatly improve our ability to assess the sublethal effects of exposure to hazardous substances. We must envision their promise for addressing these problems and identify the most urgent directions for future research.

\section{Link between Genotoxic Responses and Reproductive Success}

In the early 1990s, studies began to associate environmental contamination with altered reproductive performance in wild populations of fish, amphibians, reptiles and birds (Colborn et al., 1993).

Genotoxic exposure can act as a selective force by eliminating sensitive genotypes, or by reducing the number of offspring that they contribute to the next generation. The 
result is a reduction in the total genetic variation within that population or a shift in genotypic frequencies. Genetic variation provides the requisite flexibility for a population to persist in the face of variable biotic and abiotic selective forces over time. Reduced variation can thus lead to increased rate of extinction.

Little has been done to assess the relationships between biomarkers of biologically effective lose and any measure of reproductive success. However, evidence that relates alterations in reproductive success to changes at the population level indicates the need for such markers. Numerous specific avenues of research could strengthen the use of biomarkers to predict reproductive effects. For example, promising future research might include measures of alterations in specific genes which are known to result in dysfunctional gametes or abnormal embryonic development. In general, there is a need for studies of linkages between exposure to contaminants, increases in frequencies of biomarkers, and reduced reproductive success with a select array of contaminants, biomarkers, and species.

The health effects of pesticide exposures on male reproduction represent a topic of considerable concern in environmental, occupational and reproductive epidemiology. In recent years, scientists have become more aware of the fact that human-made chemicals may disrupt reproductive function in both wildlife and humans (Colborn et al., 1993; Moline et al., 2000).

The research to understand the relationships between genotoxic responses and measures of reproductive success has its roots in an extensive literature on nonmammalian animal models in radiobiology and chemical carcinogenesis. With the development of new animal models in genetic ecotoxicology, new relationships between genotoxic responses and measures of reproductive success begin to emerge.

Genotoxic effects on amphibians are being considered in laboratory from an ecological perspective. Although other investigators evaluated genotoxic effects in amphibia exposed to mutagenic chemicals (Siboulet et al., 1984), none has determined whether genotoxic responses are predictive of detrimental reproductive effects. Studies are underway to determine whether there are correlations between frequencies of micronuclei in circulating erythrocytes, DNA adducts in liver, wet weight at metamorphosis, and time to metamorphosis of Xenopus laevis tadpoles following the exposure to benzo- $\alpha$-pyrene.

Spermatogenesis is a remarkable process that requires exquisite control and synchronization of germ cell development. It is prone to frequent error, as paternal infertility contributes to $30-50 \%$ of all infertility cases; yet, in many cases, the mechanisms underlying its causes are unknown. Germ cell development is a critical period during which epigenetic patterns are established and maintained. The progression from diploid spermatogonia to haploid spermatozoa involves stage- and testis-specific gene expression, mitotic and meiotic division, and the histone-protamine transition. All are postulated to engender unique epigenetic controls. Underscoring the importance of understanding how epigenetic marks are set and interpreted is evidence that abnormal epigenetic programming of gametes and embryos contributes to heritable instabilities in subsequent generations. Numerous studies have documented the existence of transgenerational consequences of maternal nutrition, or other environmental exposures, but it is only now recognized that there are sex-specific male-line transgenerational responses in humans and other species. Epigenetic events in the testis have just begun to be studied. New work on the function of specific histone modifications, chromatin modifiers, DNA methylation, and the impact of the environment on developing sperm 
suggests that the correct setting of the epigenome is required for male reproductive health and the prevention of paternal disease transmission (Godman et al., 2009).

Epigenetics provides a means of understanding how environmental factors might alter heritable changes in gene expression without changing DNA sequence, and hence the origin, of some diseases that are not explained by conventional genetic mechanisms. Various animal models have been described which lend themselves particularly well to studying this link between epigenetics and development abnormalities, because particular changes in DNA methylation patterns can be linked to a broad spectrum of heritable pathologies (Rosenfeld, 2010).

When the term epigenetics was originally introduced by Waddington (1939), it referred to any causal mechanisms that act on genes to govern a resulting phenotype. This definition was refined by Holliday (1987) to implicate DNA methylation changes that result in altered gene expression and later broadened to explain how the expression of a gene might be changed and then stably maintained by any modification that does not mutate the nucleotide sequence of the gene itself (Egger et al., 2004; Esteller, 2003; Feil, 2006; Serman et al., 2006). However, even this more expansive definition has needed further refinement as the term epigenetics began to be employed to include any manner of change that caused alterations in gene expression. A more restricted definition of epigenetics is a mitotically or meiotically heritable change in gene expression that occurs independently of an alteration in DNA sequence (Younson and Whitelaw, 2008).

Jean-Baptiste Lamarck has become famous for his theory regarding the inheritance of acquired characteristics, which suggests that individuals can pass on certain features that they acquired during their lifetime to their offspring (Costa, 2008). Some of the examples he chose, including the gradual lengthening of the neck of the giraffe as a result of its foraging lifestyle, fell into disfavor, first as a result of Darwin's theory of natural selection and later by the implications of Mendelian inheritance and the notion of the gene. However, inheritance of acquired characteristics has gradually acquired new currency. Thus, there are several examples of transgenerational inheritance of phenotype, which elude conventional genetic inheritance patterns and can probably be explained on the basis of inherited epigenetic modifications of the genome. Such inheritance patterns do not involve a change in DNA sequence but survive meiosis and can be passed through the maternal or paternal germ lines. One hypothesis to account for why transgenerational effects have evolved, is the idea that the transfer of epigenetic information across generations might confer "memory" of environmental stresses experienced in earlier generations, thereby preserving a rapid response to this stressor in subsequent generations (Molinier et al., 2006; Rosenfeld, 2010).

Exposure to a range of toxicants, including vinclozolin (Crews et al., 2007; Nilson et al., 2008), diethylstilbestrol (DES) (Newbold et al., 2006; Walker and Haven, 1997; Newbold et al., 2000), methoxychlor (Anway et al., 2005), and chromium (Cheng et al., 2004), can result in transgenerational disease states, including testis defects, kidney disease, reproductive cancer development, and immune abnormalities, which in many cases are due to epigenetic alterations within the male germ line, but the transgenerational effects of DES (Walker and Haven, 1997 ) and vinclozolin (Nilsson et al., 2008) can also be passed through the female germ line.

All these studies show that environmental factors may influence the epigenetic state and that these epigenetic modifications may be inherited through the male germ line and passed onto more than one generation. Paternal effects have further highlighted the 
importance of research into epigenetic regulation and male fertility. The concept that untransmitted alleles passed through the male germ line can affect the phenotype of the next generation is a new and exciting area of research.

The 2007 Summit on "Environmental Challenges to Reproductive Health and Fertility" convened scientists, health care professionals, community groups, political representatives and the media to hear presentations on the impact of environmental contaminants on reproductive health and fertility and to discuss opportunities to improve health through research, education, communication and policy. Environmental reproductive health focuses on exposures to environmental contaminants, particularly during critical periods of development, and their potential effects on future reproductive health, including conception, fertility, pregnancy, adolescent development and adult health (Woodruff et al., 2008).

The Summit provided a view of critical scientific information that underscored the need for further efforts in areas to improve reproductive health. One common theme throughout the Summit was communication and collaboration. Scientists bring unique and important contributions to studying the impact of environmental contaminants on reproductive health.

\section{Conclusions}

The ecological assessment of territories exposed to anthropogenic influences must involve evaluation of the mutagenic potential of the environment. The assessment of genetic effects of environmental pollution on man is methodologically difficult and expensive; hence it is expedient to use indicator animal species for ecogenetic monitoring. Mass species of anurans are promising for this purpose, as specific features of their life cycle make them convenient for assessing the state of both terrestrial and aquatic ecosystems.

Amphibians are considered uniquely sensitive to man-made changes in the environment. Their porous skin is vulnerable to water borne toxins and infections, and their reliance on two habitats (water and land) means they cannot survive properly without both. Embryos and larvae of amphibians with external fertilization and development are susceptible to environmental pollutants due to direct exposure to the environment. Therefore, amphibians are regarded as good sentinel animals for environmental pollution. In addition, sex differentiation and sex organ development of $X$. laevis are sensitive to sex hormones and endocrine disruptors with sex hormone activities, which enable $X$. laevis to be used in studies on sex hormone disruption and reproductive toxicity of endocrine disruptors. Metamorphic development of $X$. laevis is very sensitive to thyroid hormones and thyroid disruptors, which enables $X$. laevis to be used for evaluating thyroid disruptors. Also, X. laevis ecotoxicology can be linked with amphibian population declines and malformed frog occurrence, being one of the hotspots in ecology. Thus, more and more laboratories have introduced $X$. laevis to ecotoxicological study.

Russell Mittermeier, President of Conservation International, said: "Amphibians are one of nature's best indicators of overall environmental health. Their catastrophic decline serves as a warning that we are in a period of significant environmental degradation." (Conor, 2004)

Researchers must be committed to providing long-term monitoring and rigorous investigation of the causes of declines in the especially sensitive amphibian component 
of the aquatic and terrestrial ecosystems worldwide. Scientists need to move forward with multi-disciplinary research that recognizes the value of animals as sentinels of environmental health. We also need to recognize that environmental protection measures that protect animal health often directly and indirectly protect our health as well.

Acknowledgments. The preparation of this review was supported by grant CNCSIS project IDEAS $142 / 2007$.

\section{REFERENCES}

[1] Alworth, L.C., Howdeshell, R., Ruhlen, R..L, Day J.K., Lubahn, D.B., Huang, T.H.M., Besch-Williford, C.L., Aal, F.S. (2002): Uterine responsiveness to estradiol and DNA methylation are altered by fetal exposure to diethylstilbestrol and methoxychlor in CD-1 mice: effects of low versus high doses. - Toxicol Appl. Pharmacol 183: 1022.

[2] Amaya, E., Kroll, K.L. (1999): A method for generating transgenic frog embryos. Methods Mol Biol. 97: 393-414.

[3] Andres, A.C., Muellener, D.B., Ryffel, G.U. (1984): Persistence, methylation and expression of vitellogenin gene derivatives after injection into fertilized eggs of Xenopus laevis. - Nucleic Acids Res 12: 2283-2302.

[4] Anway, M.D., Cupp, A.S., Uzumcu, M., Skinner, M.K. (2005): Epigenetic transgenerational actions of endocrine disruptors and male fertility. - Science 308: 1466-1469.

[5] Beck, C.W., Slack, J.M.W. (2001): An amphibian with ambition: a new role for Xenopus in the $21^{\text {st }}$ century. - Genome Biology 2(10): 1029.1-1029.5.

[6] Brown, N.M., Lamartiniere, C.A. (1995): Xenoestrogens alter mammary gland differentiation and cell proliferation in the rat. - Environmental Health Perspectives 103: 708-713.

[7] Burlibaşa, L., Cucu, N. Gavrilă, L., (2005): Amphibians as model organisms for studying the dynamics of eukaryote genetic material architecture. Wild. - Biol. Pract. 1(1): 24-32.

[8] Cheng, R.Y., Hockman, T., Crawford, E., Anderson, L.M., Shiao, Y.H. (2004): Epigenetic and gene expression changes related to transgenerational carcinogenesis. Mol Carcinog 40: 1-11.

[9] Colborn, T. (2004): Endocrine disruption overview: Are males at risk? - Adv. Exp. Med. Biol. 545: 189-201.

[10] Conor, S. (2004): Alarm as global study finds one-third of amphibian face extinction. - The Independent. UK.

[11] Conrad, J. (2010): Amphibians. - Retrieved from The Backyard Nature Website at http//:www.backyardnature.net/amphibs.htm.

[12] Costa, F.F. (2008): Non-coding RNAs, epigenetics and complexity. - Gene 410: 917.

[13] Crews, D., McLachlan, J.A. (2006): Epigenetics, Evolition, Endocrine Disruption, Health and Disease. - Endocronology 147(6):supp. S4-S10.

[14] Crews, D., Gore, A.C., Hsu, T.S., Dangleben, N.L., Spinetta, M., Schallert, T., Anway, M.D., Skinner, M.K. (2007): Transgenerational epigenetic imprints on mate preference. - Proc. Natl. Acad. Sci. U S A 104: 5942-5946.

[15] Devaux, A., Pesonen, M., Monod, G. (1997): Alkaline Comet Assay in rainbow trout hepatocytes. - Toxicology in Vitro 11: 71-79. 
[16] Djomo, J.E., Ferrier, V., Bekaert, C. (2000): Amphibian micronucleus test in vivo (Jaylet test) to evaluate the genotoxicity of petrochemical waste waters. - Bull. Environ. Contam. Toxicol. 65: 168-174.

[17] Edinger, R.S., Mambo, E., Evans, M.I. (1997): Estrogen-dependent transcriptional activation and vitellogenin gene memory. - Mol. Endocrinol. 11: 1985-1993.

[18] Egger, G., Liang, G., Aparicio, A., Jones, P.A. (2004): Epigenetics in human disease and prospects for epigenetic therapy. - Nature, 429: 457-463.

[19] Erbes, M., Wessler, A., Obst, U., Wild, A. (1997): Detection of primary DNA damage in Chlamydomonas reinhardtii by means of modified microgel electrophoresis. - Environ. Mol Mutagen 30: 448-458.

[20] Esteller, M., (2003): Relevance of DNA methylation in the management of cancer. Lancet Oncol 4: 351-358.

[21] Fei, X., Chung, Taylor, H.S. (2005): Methoxychlor disrupts uterine Hoxa10 gene expression. - Endocrinology 146: 3445-3451.

[22] Feil, R. (2006): Environmental and nutritional effects on the epigenetic regulation of genes. - Mutat. Res. 600: 46-57.

[23] Fernandez, M., L'Haridon, J., Gauthier, L., Zoll-Moreux, C. (1993): Amphibian micronucleus test(s): a simple and reliable method for evaluating in vivo genotoxic effects of freshwater pollutants and radiations. Initial assessment. - Mutat Res. 292: 83-99.

[24] Fini, J.B., Pallud-Mothré, S., Le Mével, S., Palmier, K., Havens, C.M., Le Brun, M., Mataix, V., Lemkine, G.F., Demeneix, B.A., Turque, N., Johnson, P.E. (2009): An innovative continuous flow system for monitoring heavy metal pollution in water using transgenic Xenopus laevis tadpoles. - Environ. Sci. Technol., Dec 1, 43(23): 895-900.

[25] Godet, F., Babut, M., Burnel, D., Veber, A.M., Vasseur, P. (1996): The genotoxicity of iron and chromium in electroplating effluents. - Mutat Res. 370: 19-28.

[26] Godmann, M., Lambrot, R., Kimmins, S. (2009): The dynamic epigenetic program in male germ cells: Its role in spermatogenesis, testis cancer, and its response to the environment. - Microsc. Res. Tech. 72(8): 603-19.

[27] Goldberg, E.D. (1986): The Mussel Watch concept. - Environmental Monitoring and Assessment 7: 91-103.

[28] Hayes, T., Haston, K., Tsui, M., Hoang, A., Haeffele, C., Vonk, A. (2003): Atrazineinduced hermaphroditism at $0.1 \mathrm{ppb}$ in American leopard frogs (Rana pipiens): laboratory and field evidence. - Environ. Health Perspect 111(4): 568-575.

[29] Hayes, T.B., Falso, P., Gallipeau, S., Stice, M. (2010): The cause of global amphibian declines: a developmental endocrinologist's perspective. - Journal of Experimental Biology 213 (6): 921.

[30] Hayes, T.B., Collins, A., Lee, M., Mendoza, M., Noriega, N., Stuart, A.A., Vonk, A. (2002): Hermaphroditic, demasculinized frogs after exposure to the herbicide atrazine at low ecologically relevant doses. - PNAS 99(8): 5476-5480.

[31] Holliday, R. (1987): The inheritance of epigenetic defects. - Science, 238: 163-170.

[32] Hoyer, P.B. (2001): Reproductive toxicology: Current and future directions. Biochem. Pharmacol. 62(12): 1557-1564.

[33] Huang, W.W., Yin, Y., Bi, Q., Chiang, T.C., Garner, N., Vuoristo, J., McLachlan, J.A., Ma, L., (2005): Developmental diethylstilbestrol (DES) exposure alters genetic pathways of uterine cytodifferentiation. - Mol. Endocrinol. 19: 669-682.

[34] Hussein, S.Y, .El-Nasser, M.A., Ahmed, S.M. (1996): Comparative Studies on the Effects of Herbicide Atrazine on reshwater Fish Oreochromis niloticus and Chrysichthyes auratus at Assiut, Egypt. - Bulletin of Environmental Contamination and Toxicology. 
[35] Jaylet, A., Deparis, P., Gaschignard, D.(1986): Induction of micronuclei in peripheral erythrocytes of axolotl larvae following in vivo exposure to mutagenic agents. Mutagenesis 1: 211-215.

[36] Kennerley, G.A., Parry J.M. (1994): Analysis of benzo- $\alpha$-pyrene induced mutations by the use of Restriction - Site Mutation assays in aquatic species. - Mutat. Res. 307: 223-228.

[37] Kloas, W., Lutz, I., Einspanier, R. (1999): Amphibians as a model to study endocrine disruptors: II. Estrogenic activity of environmental chemicals in vitro and in vivo. Sci. Total Environ. 12(225) (1-2): 59-68.

[38] Kohlpoth, M, Rusche, B., Nüsse, M.I. (1999): Flow cytometric measurement of micronuclei induced in a permanent fish cell line as a possible screening test for the genotoxicity of industrial waste waters. - Mutagenesis 14(4): 397-402.

[39] Krauter, P.W., Anderson, S.L., Harrison, F.L. (1987): Radiation-induced micronuclei in peripheral erythrocytes of Rana catesbeiana: an aquatic animal model for in vivo genotoxicity studies. - Environ. Mol. Mutagen. 10: 285-296.

[40] Kroll, K.L., Amaya, E. (1996): Trangenic Xenopus embryos from sperm nuclear transplantations reveal FGF signaling requirements during gastrulation. Development 122: 3173-3183.

[41] Lannov, M. (2008): University of California Press - USGS National Wildlife Health Center www.nwhc.usgs.gov.

[42] Lutz, I., Kloas, W. (1999): Amphibians as model to study endocrine disruptors: I. Environmental pollution and estrogen receptor binding. "Drugs and Hormones as Pollutants of the Aquatic Environment - Determination and Ecotoxocological Impacts" - Sci. Total Environ. 225: 49-57.

[43] Mascini, M., Palchetti, I., Marrazza, G. (2001): DNA electrochemical biosensors. Fresenius J Anal Chem. 369: 15-22.

[44] Mitchelmore, C.L., Chipman J.K. (1998): Detection of DNA strand breaks in brown trout (Salmo trutta) hepatocytes and blood cells using the single cell gel electrophoresis (comet) assay. - Aquatic Toxicol. 41: 161-182.

[45] Mitchelmore, C.L., Birmelin, C., Livingstone, D.R., Chipman, J.K. (1998): Detection of DNA strand breaks in isolated mussel (Mytilus edulis L. ) digestive gland cells using the "Comet" assay. - Ecotoxicol Environ. Saf. 41: 51-58.

[46] Moline, J.M., Golden, A., Bar-Chama, N., Smith, E., Ranch, M., Chapin, R., Perreault, S., Schrader, S., Suk, W., Landrigan, P. (2000): Exposure to hazardous substances and male reproductive health: a research framework. - Environmental Health Persepctives 108(9).

[47] Molinier, J, Ries, G, Zipfel, C, Hohn, B. (2006): Transgeneration memory of stress in plants. Nature 442: 1046-1049.

[48] Mouchet, F., Landois, P., Datsyuk, V., Puech, P., Pinelli, E., Flahaut, E., Gauthier, L. (2009): International amphibian micronucleus standardized procedure (ISO 21427-1) for in vivo evaluation of double-walled carbon nanotubes toxicity and genotoxicity in water. - Environmental toxicology DOI 10.1002/tox.20537 (article in press).

[49] Neubert, D. (2002): Reproductive toxicology: The science today. - Teratog. Carcinog. Mutagen 22(3): 159-174.

[50] Newbold, R,R,, Hanson, R.B., Jefferson, W.N., Bullock, B.C., Haseman, J., McLachlan, J.A. (2000): Proliferative lesions and reproductive tract tumors in male descendants of mice exposed developmentally to diethylstilbestrol. - Carcinogenesis 21: $1355-1363$.

[51] Newbold, R.R., Padilla-Banks, E., Jefferson, W.N. (2006): Adverse effects of the model environmental estrogen diethylstilbestrol are transmitted to subsequent generations. - Endocrinology 147: 11-17. 
[52] Nilsson, E.E., Anway, M.D., Stanfield, J., Skinner, M.K. (2008): Transgenerational epigenetic effects of the endocrine disruptor vinclozolin on pregnancies and female adult onset disease. - Reproduction 135: 713-721.

[53] Ouellet, M. (2000): Amphibian deformities: current state of knowledge. - In: Ecotoxicology of Amphibians and Reptiles (Sparling, D.W., Linder, G., Bishop, C.A., eds). Pensacola, FL:Society of Environmental Toxicology and Chemistry (SETAC), 617-646.

[54] Ouellet, M., Bonin, J., Rodrigue, J., DesGranges, J., Lair, S. (1997): Hindlimb deformities (ectromelia, ectrodactyly) in free living anurans from agricultural habitats. - J. Wildl. Dis. 33: 95-104.

[55] Pandrangi, R., Petras, M., Ralph, S., Vrzoc, M. (1995): Alkaline single cell (comet) assay and genotoxicity monitoring using bullhead and carp. - Environ. Mol Mutagen. 26: 345-356.

[56] Parsons, B.L., Heflich, R.H. (1998): Detection of basepair substitution mutation at a frequency of 1 x 10(-7) by combining two genotypic selection methods, MutEx enrichment and allele-specific competitive blocker PCR. - Environ. Mol Mutagen. 32: 200-211.

[57] Pavlica, M., Klobucar, G.I.V., Mojas, N., Erben, R., Papes, D. (2001): Detection of DNA damage in haemocytes of zebra mussel using comet assay. - Mutat. Res. 490: 209-214.

[58] Pesch, B, Bruning, T, Frentzel-Beyme, R. (2004): Challenges to envi-ronmental toxicology and epidemiology: Where do we stand and which way do we go? Toxicol. Lett. 151(1): 255-266.

[59] Picco, A., Collins, J.P. (2008): Amphibian commerce as a likely source of pathogen pollution. - Conservation Biology 22(6): 1582-1589.

[60] Ralph, S., Petras, M. (1998): Caged amphibian tadpoles and in situ genotoxicity monitoring of aquatic environments with the alkaline single cell gel electrophoresis (comet) assay. - Mutat. Res. 413: 235-250.

[61] Risso-de Faverney, C.A., Devaux, M., Lafaurie, J.P., Girard, B., Bailly, R., Rahmani (2001): Cadmium induces apoptosis and genotoxicity in rainbow trout hepatocytes through generation of reactive oxygene species. - Aquat. Toxicol. 53: 65-76.

[62] Rosenfeld, C.S. (2010): Animal Models to Study Environmental Epigenetics. Biology of Reproduction 82(3): 473-488.

[63] Sánchez, P., Llorente, M.T., Castano, A. (2000): Flow cytometric detection of micronuclei and cell cycle alterations in fish-derived cells after exposure to three model genotoxic agents: mitomycin $\mathrm{C}$, vincristine sulfate; and benzo- $\alpha$-pyrene. Mutat. Res. 65: 113-122.

[64] Schnurstein, A., Tischmeyer, A., Braunbeck, T. (2001): Tail moment versus tail length - Application of an in vitro version of the comet assay in biomonitoring for genotoxicity in native surface waters using primary hepatocytes and gill cells from zebrafish (Danio rerio). - Ecotox. Environ. Saf. 49: 187-196.

[65] Serman, A, Vlahovic, M., Serman, L., Bulic-Jakus, F., (2006): DNA methylation as a regulatory mechanism for gene expression in mammals. - Coll. Antropol. 30: 665671.

[66] Siboulet, R, Grinfeld, S., Deparis, P., Jaylet, A. (1984): Micronuclei in red blood cells of the newt Pleurodeles waltl Michah: induction with X-rays and chemicals. - Mutat. Res. 125: 275-281.

[67] Singh, N.P., Danner, D.B., Tice, R.R., McCoy, M.T., Collins, G.D., Schneider, E.L. (1989): Abundant alkali-sensitive sites in DNA of human and mouse sperm. Experimental Cell. Research 184: 461-470.

[68] Solomon, K, Carr, J.A., Du Preez, L.H., Giesym J.P., Gross, T.S., Kendall, R.J., Smith, E.E., Van Der Kraak, G.J. (2005): Ecotoxicological Risk Assessment of 
Atrazine in Amphibians. - In: Environmental Fate and Safety Management of Agrochemicals Chapter 12, pp 124-137, ACS Symposium Series, Vol. 899.

[69] Solomon, K.R., Carr, J.A.Du, Preez, L.H., Giesy, J.P., Kendall, R.J., Smith, E.E., Van Der Kraak, G.J., (2008): Effects of Atrazine on Fish, Amphibians, and Aquatic Reptiles: A Critical Review. - Critical Reviews in Toxicology 38(9):721-772.

[70] Tice, R. (1998): Protocol for the application of the $\mathrm{pH}>13$ alkaline single cell gel (SCG) assay to the detection of DNA damage in mammalian cells. - Integrated Laboratory Systems, Research Triangle Park.

[71] Tice, R.R., Agurell, E., Anderson, D., Burlinson, B., Hartmann, A., Kobayashi, H., Miyamae, Y., Rojas, E., Ryu, J-C., Sasaki, Y.F. (2000): Single cell gel/comet assay: Guidelines for the in vitro and in vivo genetic toxicity testing. - Environmental and Molecular Mutagenesis 35: 206-221.

[72] Ulger, M. (2003): Fundamental in Ecotoxicology. - Second Ed., Lewis Publisher.

[73] Villarini, M. (1998): Detection of DNA damage in stressed trout nucleated erythrocytes using the comet assay: protection by nitroxide radicals. - Free Rad. Biol. Med. 24: 1310-1315.

[74] Waddington, C.H. (1939): Introduction to Modern Genetics. - London, England: George Allen and Unwin, Ltd.

[75] Waddington, C.H. (1942): Canalization of development and the inheritance of acquired characters. - Nature 150: 563-565.

[76] Waddington, C.H. (1953): Genetic assimilation of an acquired character. - Evolution 7: 118-126.

[77] Walker, B.E., Haven, M.I. (1997): Intensity of multigenerational carcinogenesis from diethylstilbestrol in mice. - Carcinogenesis 18: 791-793.

[78] Wilhelms, K.W., Cutler, S.A., Proudman, J.A., Anderson, L.L., Scanes, C.G. (2005): Atrazine and the Hypothalamo-Pituitary-Gonadal Axis in Sexually Maturing Precocial Birds: Studies in Male Japanese Quail. - Toxicological Sciences 86(1): 152-160.

[79] Woodruff, T. J., Carlson, A., Schwartz, J.M., Giudice, L.C. (2008): Proceedings of the Summit on Environmental Challenges to Reproductive Health and Fertility: Executive Summary. - Fertil. Steril. 89(2): 281-300.

[80] Youngson, N.A., Whitelaw, E., (2008): Transgenerational epigenetic effects. - Annu. Rev. Genomics Hum. Genet. 9: 233-257.

[81] Zhanfen, Q., Xiaobai, X. (2006): Application of Xenopus laevis in ecotoxicology (I). Introduction and quality control of laboratory animal. - Chinese Sci. Bulletin 51(11): 1273-1280. 